\title{
Statistical Optimization of Medium Components by Response Surface Methodology to Enhance Menaquinone-7 (Vitamin $\mathrm{K}_{2}$ ) Production by Bacillus subtilis ${ }^{\mathrm{S}}$
}

\author{
Wei-Jie $\mathrm{Wu}^{1,2}$ and Byung-Yong $\mathrm{Ahn}^{3 *}$ \\ ${ }^{1}$ Institute of Food Science, Zhejiang Academy of Agricultural Sciences, Hangzhou, Zhejiang 310021, P.R. China \\ ${ }^{2}$ Key Laboratory of Post-Harvest Handling of Fruits, Ministry of Agriculture, Hangzhou, Zhejiang 310058, P.R. China \\ ${ }^{3}$ Department of Oriental Medicine Resources, Chonbuk National University, Iksan 570-752, Republic of Korea
}

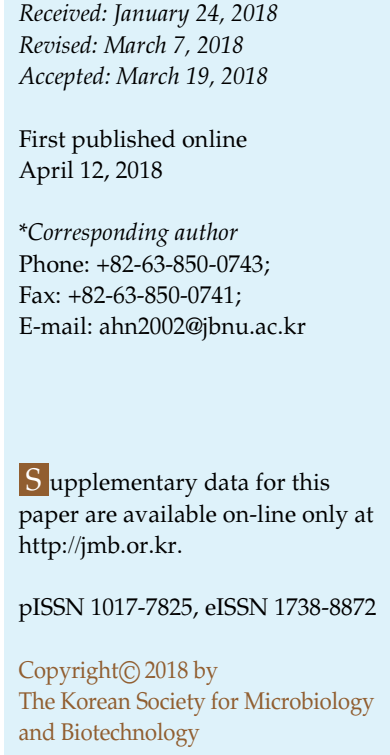

S upplementary data for this paper are available on-line only at http://jmb.or.kr.

pISSN 1017-7825, eISSN 1738-8872

Copyright(C) 2018 by

The Korean Society for Microbiology and Biotechnology

\begin{abstract}
Optimization of the culture medium to maximize menaquinone-7 (MK-7) production by Bacillus subtilis strain KCTC $12392 \mathrm{BP}$ in static culture was carried out using statistical experimental methods, including one factor at a time, fractional factorial design, and response surface methodology (RSM). Maltose (carbon source), tryptone (nitrogen source), and glycerol (activator) were identified as the key medium components for MK-7 synthesis by the fractional factorial design, and were selected for statistical optimization by RSM. The statistical analysis indicated that, in the range that was studied, maltose, tryptone, and glycerol were all critical factors having profound effects on the production of MK-7, with their coefficients for linear and quadratic all significant at the $p<0.05$ level. The established model was efficient and feasible, with a determination coefficient $\left(R^{2}\right)$ of 0.9419 . The predicted concentrations of maltose, tryptone, and glycerol in the optimal medium were determined as $36.78,62.76$, and $58.90 \mathrm{~g} / \mathrm{l}$, respectively. In this optimized medium, the maximum yield of MK-7 reached a remarkably high level of $71.95 \pm 1.00 \mu \mathrm{g} / \mathrm{ml}$ after 9 days of static fermentation, which further verified the practicability of this optimized strategy.
\end{abstract}

Keywords: Menaquinone-7, vitamin $\mathrm{K}_{2}$, Bacillus subtilis, statistical optimization

\section{Introduction}

Vitamin $\mathrm{K}$ is essential for the coagulation of blood. In fact, the designated $K$ is an abbreviation of the German word "Koagulationsvitamin" [1]. There are two types of vitamin $\mathrm{K}$ isolated from nature. Vitamin $\mathrm{K}_{1}$ (phylloquinone) is synthesized mainly by plants, whereas vitamin $\mathrm{K}_{2}$ (menaquinone) is mainly contained in animals and microorganisms [2]. Menaquinone-7 (MK-7), a valuable member of the vitamin $K_{2}$ family, has a significant effect in the prevention of cancer [3], osteoporosis [4], and cardiovascular disease [5], which are public health issues with numerous epidemiological links and important economic consequences [6]. MK-7 is available in food products such as meat, cheese, and fermented soybean. The latter has the highest MK-7 concentration formulated as natto in Japan at
$12.98 \mu \mathrm{g} / \mathrm{g}$ [7] and cheonggukjang in Korea at $12.47 \mu \mathrm{g} / \mathrm{g}$ [8]. Nevertheless, the MK-7 content from these dietary sources is not as sufficient for therapeutic applications to treat osteoporosis and cardiovascular disease. Therefore, industrial-scale production of MK-7 as a dietary supplement is desirable.

To match the practical application in industry, MK-7 is produced mainly by liquid-state fermentation by using Bacillus species, particularly Bacillus subtilis [9], B. amyloliquefaciens [10], and B. licheniformis [11]. Extensive research studies have sought to improve the production of MK-7, by isolation of novel high productivity strains [10], genetic mutations $[2,12]$, and the optimization of culture medium and operating conditions $[8,9]$. However, until recently, the general practice to optimize the medium components for MK-7 production was to use one factor at a time, with 
only limited study involving statistical and mathematical techniques [13].

In this study, response surface methodology (RSM) was used to investigate the interactive effects of variable nutrients in the culture medium and their effects on the production of MK-7. RSM reduces the number of experimental trials needed to evaluate multiple parameters and their interactions, and therefore has been used to successfully model and optimize biochemical and biotechnological processes related to food systems $[14,15]$. In order to maximize the MK-7 yield, a three-step RSM was applied to obtain the optimal medium compositions. First, three key nutrients having a significant effect on MK-7 production were identified and determined by a fractional factorial design. Second, a factorial central composite rotator design (CCRD) was performed to study the relationship between MK-7 yield and the three key factors to achieve the optimum concentration of each factor. Finally, the validity of this model was determined. The present work describes the successful optimization of a culture medium for the production of MK-7 by B. subtilis.

\section{Materials and Methods}

\section{Reagents}

Authentic MK-7 was purchased from ChromaDex Inc. (USA). Glycerol, glucose, maltose, and Tween 20, 40, 60, and 80 were bought from Junsei Chemical Co. (Japan). Beef extract, tryptone, yeast extract, soytone, and tryptic soy broth were purchased from Difco (USA). 1,4-Dihydroxy-2-naphthoic acid and dipicolinic acid were obtained from Sigma-Aldrich Chemical Co. (USA). All the other chemicals were of analytical or HPLC grade.

\section{Microorganisms and Fermentation Process}

The B. subtilis strain KCTC 12392BP used in the present study was isolated from commercial cheonggukjang available in the Korean market. The isolate has been deposited at Korea Collection for Type Cultures (Korea Research Institute of Bioscience and Biotechnology, Korea). Soybean extract (boiled soybean soup, 10\% $(\mathrm{w} / \mathrm{v}))$ was used as the basal liquid medium, in which the MK-7 synthesis was carried out [10]. Twenty milliliters of the soybean extract $(\mathrm{pH} 7.0)$ in a 100-ml flask was autoclaved and inoculated with $200 \mu \mathrm{l}(1 \%(\mathrm{v} / \mathrm{v}))$ of the precultured cell suspension $\left(10^{9}\right.$ cells $\left./ \mathrm{ml}\right)$. After reciprocal shaking for $6 \mathrm{~h}$, fermentation was conducted statically at $40^{\circ} \mathrm{C}$ for 5 days.

\section{MK-7 Analysis}

The analysis of MK-7 was carried out according to a previous reported procedure [8], with slight modifications. 2-Propanol $(2.4 \mathrm{ml})$ and $n$-hexane $(4.8 \mathrm{ml})$ were mixed with $2 \mathrm{ml}$ of the fermented medium. The mixture was vigorously shaken and kept standing for $1 \mathrm{~h}$. After centrifugation at 3,000 rpm for $10 \mathrm{~min}$
(Union 32R; Hail, Korea), the organic phase was collected and evaporated under nitrogen gas. The oil residue was dissolved in ethanol. After filtering with $0.45-\mu \mathrm{m}$ syringe filters (Millipore, USA), the sample solution was injected into a high-performance liquid chromatography system with a model 600 Controller gradient pump equipped with a degasser, and model 717 Plus autosampler (Waters, USA). The analytical column was a NovaPak $\mathrm{C}_{18}$ column (WAT086344, $3.9 \times 150 \mathrm{~mm}$; Waters, USA), and the temperature was fixed at $40^{\circ} \mathrm{C}$. After reduction by platinum black (reduction column, $4.6 \times 10 \mathrm{~mm}$; JIScience, Korea), the peaks were detected with a model 474 scanning fluorescence detector (Waters, USA) using an excitation and emission wavelength of $320 \mathrm{~nm}$ and $430 \mathrm{~nm}$, respectively. The mobile phase was 100\% methanol at a flow rate of $1.0 \mathrm{ml} / \mathrm{min}$, and the injection volume of the sample was $20 \mu$ l. The concentration of MK in the medium was expressed as $\mu \mathrm{g} / \mathrm{ml}$ of culture medium.

\section{Experimental Design}

Many different medium components could affect the synthesis of MK-7. These include carbon source, nitrogen source, phosphate source, surfactants, and activators [9, 13, 16-18]. In preliminary experiments, the medium constituents were optimized by the onefactor-at-a-time (OFAT) method. It varies only one factor or variable at a time while keeping the other factors constant. The OFAT method can identify the impact of each element of given conditions independently, but it requires a considerable amount of work, and interactions occurring between factors cannot be assessed [19]. Secondly, fractional factorial design was used to screen and evaluate the important medium components that influence the production of MK-7. In order to reduce the number of experimental runs, each factor was set to contain three levels and a $2^{7-4}$ fractional factorial design was considered, with one center point run for statistical reasons (Table 1). Finally, factorial CCRD was used to find the optimal conditions of the significant variables in this study. According to the results of the fractional factorial design, the three most important factors were selected, and a factorial CCRD for these three factors with replicates at the center point was performed. The CCRD maximizes the amount of information that can be obtained while limiting the number of individual experiments required [20]. In this study, the experimental design contained 16 trials, and the value of the responses was the mean of triplicate values. The second-order polynomial coefficients were calculated and analyzed using the Design Expert statistical package (ver. 8.0.6; Stat-Ease Inc., USA). Statistical analysis of the model was performed to evaluate the analysis of variance (ANOVA).

\section{Model Verification}

The optimum concentrations of studied medium components were obtained by solving the regression equation. Subsequently, the MK-7 content synthesized in the optimal culture medium was investigated, and the experimental and predicted values were compared to determine the validity of the model. 
Table 1. Fractional factorial design and the corresponding experimental results.

\begin{tabular}{ccccccccc}
\hline Variables $(\mathrm{g} / \mathrm{l})$ & \multicolumn{1}{c}{ Results } \\
\hline Trial No. & $\mathrm{I}$ & $\mathrm{II}$ & $\mathrm{III}$ & $\mathrm{IV}$ & $\mathrm{V}$ & $\mathrm{VI}$ & $\mathrm{VII}$ & $\mathrm{MK}-7(\mu \mathrm{g} / \mathrm{ml})$ \\
\hline 1 & $-(40)$ & $-(10)$ & $-(0.5)$ & $-(4)$ & $-(40)$ & $-(0.33)$ & $-(0.010)$ & $23.19 \pm 0.63$ \\
2 & $-(40)$ & $-(10)$ & $-(0.5)$ & $+(6)$ & $+(60)$ & $+(0.99)$ & $+(0.030)$ & $18.84 \pm 0.01$ \\
3 & $-(40)$ & $+(30)$ & $+(1.5)$ & $-(4)$ & $-(40)$ & $+(0.99)$ & $+(0.030)$ & $25.99 \pm 2.16$ \\
4 & $-(40)$ & $+(30)$ & $+(1.5)$ & $+(6)$ & $+(60)$ & $-(0.33)$ & $-(0.010)$ & $24.43 \pm 1.72$ \\
5 & $+(60)$ & $-(10)$ & $+(1.5)$ & $-(4)$ & $+(60)$ & $-(0.33)$ & $+(0.030)$ & $13.74 \pm 1.37$ \\
6 & $+(60)$ & $-(10)$ & $+(1.5)$ & $+(6)$ & $-(40)$ & $+(0.99)$ & $-(0.010)$ & $19.30 \pm 1.12$ \\
7 & $+(60)$ & $+(30)$ & $-(0.5)$ & $-(4)$ & $+(60)$ & $+(0.99)$ & $-(0.010)$ & $19.53 \pm 1.24$ \\
8 & $+(60)$ & $+(30)$ & $-(0.5)$ & $+(6)$ & $-(40)$ & $-(0.33)$ & $+(0.030)$ & $27.31 \pm 1.45$ \\
9 & $0(50)$ & $0(20)$ & $0(1.0)$ & $0(5)$ & $0(50)$ & $0(0.66)$ & $0(0.015)$ & $27.43 \pm 1.29$ \\
\hline
\end{tabular}

Code I, maltose; code II, tryptone; code III, $\mathrm{NaH}_{2} \mathrm{PO}_{4}$; code IV, Tween 80; code V, glycerol; code VI, dipicolinic acid; code VII, 1,4-dihydroxy-2-naphthoic acid.

\section{Results and Discussion}

\section{Factor Identification}

In the preliminary study, seven factors that displayed profound effects on MK-7 synthesis were selected by using the OFAT method: maltose (Factor I), tryptone (Factor II), $\mathrm{NaH}_{2} \mathrm{PO}_{4}$ (Factor III), and Tween 80 (Factor IV) were selected as the appropriate candidate carbon source, nitrogen source, phosphate source, and surfactant, respectively. Additionally, glycerol (Factor V), dipicolinic acid (Factor VI), and 1,4-dihydroxy-2-naphthoic acid (Factor VII) had the capability to enhance the production of MK-7 by B. subtilis. The production of MK-7 was increased from $7.56 \mu \mathrm{g} / \mathrm{ml}$ in the initial medium composition to $27.15 \mu \mathrm{g} / \mathrm{ml}$ by OFAT method optimization (Supplementary data). Glycerol has been reported to play an important role in MK-7 production and has been widely used as the optimal carbon source $[8,9,13]$. Compared with glycerol $(15.65 \mu \mathrm{g} / \mathrm{ml})$, maltose $(16.45 \mu \mathrm{g} / \mathrm{ml})$ showed the most significant effect in this

Table 2. ANOVA table for the experiment in the step of factor identification.

\begin{tabular}{lccc}
\hline $\begin{array}{c}\text { Source of } \\
\text { variation }\end{array}$ & $\begin{array}{c}\text { Stdized } \\
\text { effects }\end{array}$ & $\begin{array}{c}\text { Sum of } \\
\text { square }\end{array}$ & $\begin{array}{c}\text { Percentage } \\
\text { contribution (\%) }\end{array}$ \\
\hline Maltose & -3.16 & 30.03 & 11.60 \\
Tryptone & 5.57 & 62.04 & 35.93 \\
$\mathrm{NaH}_{2} \mathrm{PO}_{4}$ & -1.38 & 3.80 & 2.30 \\
Tween 80 & 1.83 & 6.69 & 3.87 \\
Glycerol & -4.79 & 45.86 & 26.56 \\
Dipicolinic acid & -1.27 & 3.24 & 1.88 \\
DHNA & -0.11 & 0.03 & 0.02 \\
\hline
\end{tabular}

DHNA: 1,4-dihydroxy-2-naphthoic acid. study, and was selected as the optimal carbon source (Supplementary data). It has been reported that the effect of glycerol is not to promote cell growth, but to increase the yield of MK on a per-cell basis [12]. Moreover, glycerol was used as an additional activator, considering its association with MK-7 production [16].

The fractional factorial design enables the identification of interactions between factors more accurately and allows determining the effect of one factor among the other factors studied [21]. According to Tables 1 and 2, the highest yield of MK-7 was obtained in trial 9 culture medium $(27.43 \mu \mathrm{g} / \mathrm{ml})$, where the three most significant factors are maltose, tryptone, and glycerol with the percentage contribution of $11.60 \%, 35.93 \%$, and $26.56 \%$, respectively, which is in agreement with previous reports; carbon and nitrogen sources can have significant effects on the production of MK-7 [13]. On the basis of these results, maltose, tryptone, and glycerol were identified as the most important medium components for MK-7 synthesis by B. subtilis (KCTC 12392BP) and were selected for statistical optimization by RSM.

\section{Fitting the Models}

A factorial CCRD was employed to analyze the interactive effects of these three major components (factor A: maltose; factor B: tryptone; factor C: glycerol) and to determine the optimal level of each factor. On the basis of the fractional factorial results, the level planning of the CCRD with each factor containing five levels $(-\alpha,-1,0,+1,+\alpha)$ was designed as shown in Table 3. Meanwhile, the other four relatively unimportant factors of $\mathrm{NaH}_{2} \mathrm{PO}_{4}$, Tween 80, dipicolinic acid, and 1,4-dihydroxy-2-naphthoic acid were fixed at a concentration of 1.0, 5.0, 0.66, and $0.015 \mathrm{~g} / 1$, respectively. Each trial in the experimental layout was conducted in 
Table 3. Experimental design and central composite design results.

\begin{tabular}{ccccc}
\hline \multirow{2}{*}{ Run } & \multicolumn{3}{c}{ Medium composition $(\mathrm{g} / \mathrm{l})$} & Experimental \\
\cline { 2 - 3 } & Maltose (A) & Tryptone (B) & Glycerol $(\mathrm{C})$ & MK-7 $(\mu \mathrm{g} / \mathrm{ml})$ \\
\hline 1 & $-1(20)$ & $-1(40)$ & $-1(20)$ & $42.38 \pm 0.02$ \\
2 & $+1(60)$ & $-1(40)$ & $-1(20)$ & $44.99 \pm 2.18$ \\
3 & $-1(20)$ & $+1(80)$ & $-1(20)$ & $38.55 \pm 0.58$ \\
4 & $+1(60)$ & $+1(80)$ & $-1(20)$ & $57.80 \pm 0.74$ \\
5 & $-1(20)$ & $-1(40)$ & $+1(60)$ & $51.99 \pm 2.16$ \\
6 & $+1(60)$ & $-1(40)$ & $+1(60)$ & $51.72 \pm 0.33$ \\
7 & $-1(20)$ & $+1(80)$ & $+1(60)$ & $59.64 \pm 0.94$ \\
8 & $+1(60)$ & $+1(80)$ & $+1(60)$ & $57.97 \pm 2.18$ \\
9 & $-\alpha(6.36)$ & $0(60)$ & $0(40)$ & $45.79 \pm 1.23$ \\
10 & $+\alpha(73.64)$ & $0(60)$ & $0(40)$ & $53.97 \pm 1.22$ \\
11 & $0(40)$ & $-\alpha(26.36)$ & $0(40)$ & $47.29 \pm 2.60$ \\
12 & $0(40)$ & $+\alpha(93.64)$ & $0(40)$ & $52.18 \pm 1.33$ \\
13 & $0(40)$ & $0(60)$ & $-\alpha(6.36)$ & $47.74 \pm 1.08$ \\
14 & $0(40)$ & $0(60)$ & $+\alpha(73.64)$ & $62.51 \pm 1.87$ \\
15 & $0(40)$ & $0(60)$ & $0(40)$ & $62.28 \pm 1.74$ \\
16 & $0(40)$ & $0(60)$ & $0(40)$ & $61.29 \pm 2.42$ \\
\hline
\end{tabular}

triplicate, and the mean of the three is presented in Table 3.

The results of the second-order response surface model fitting in the form of ANOVA are presented in Table 4. ANOVA of the quadratic regression model demonstrated that the model was highly significant, as evident from the $F$-value of 10.81 with a very low probability value [ $p>$ $F)=0.0045$ ], indicating that there was only a small chance $(0.45 \%)$ that a "model $F$-value" of this size could occur because of noise. The $p$-values are used as a tool to check the significance of each independent variable, with smaller $p$-values indicating a greater significance of the corresponding variable [22]. In this study, the $p$-value was $<0.0100$, which indicated that the model terms were highly significant. This study determined that $\mathrm{A}, \mathrm{B}, \mathrm{C}, \mathrm{AC}, \mathrm{A}^{2}, \mathrm{~B}^{2}$, and $\mathrm{C}^{2}$ were significant model terms. In addition, the linear of glycerol $(C)$, and quadratic of maltose $\left(\mathrm{A}^{2}\right)$ and tryptone $\left(\mathrm{B}^{2}\right)$ were more significant $(p<0.01)$ than the other factors. These results suggest that the concentration of glycerol had a direct relationship with the production of MK-7 in this particular complex medium, which is consistent with the previous description that MK-7 production was mainly affected by the glycerol concentration [16]. The concentration of maltose and tryptone were significant at the linear level, and more significant at the quadratic level, meaning that they can act as limiting nutrients and that a little variation in their concentration will alter the product formation rate.
Table 4. ANOVA results for the response surface quadratic model.

\begin{tabular}{llllll}
\hline \multicolumn{1}{c}{ Source } & $\begin{array}{l}\text { Sum of } \\
\text { squares }\end{array}$ & DF $^{\mathrm{a}}$ & $\begin{array}{c}\text { Mean } \\
\text { square }\end{array}$ & $F$-value & $p$-value \\
\hline Model & 784.77 & 9 & 87.20 & 10.81 & $0.0045^{* *}$ \\
A-Maltose & 83.02 & 1 & 83.02 & 10.30 & $0.0184^{*}$ \\
B-Tryptone & 70.73 & 1 & 70.73 & 8.77 & $0.0252^{*}$ \\
C-Glycerol & 285.54 & 1 & 285.54 & 35.41 & $0.0010^{* *}$ \\
AB & 29.03 & 1 & 29.03 & 3.60 & 0.1065 \\
AC & 70.82 & 1 & 70.82 & 8.78 & $0.0252^{*}$ \\
BC & 3.04 & 1 & 3.04 & 0.38 & 0.5618 \\
$\mathrm{~A}^{2}$ & 170.22 & 1 & 170.22 & 21.11 & $0.0037^{* *}$ \\
$\mathrm{~B}^{2}$ & 174.21 & 1 & 174.21 & 21.61 & $0.0035^{* *}$ \\
$\mathrm{C}^{2}$ & 54.70 & 1 & 54.70 & 6.78 & $0.0404^{*}$ \\
Residual & 48.38 & 6 & 8.06 & & \\
Lack of fit & 47.89 & 5 & 9.58 & 19.54 & 0.1700 \\
Pure error & 0.49 & 1 & 0.49 & & \\
Cor total & 833.15 & 15 & & & \\
$R^{2}$ & 0.9419 & & Adj $\mathrm{R}^{2}$ & 0.8548 & \\
\hline
\end{tabular}

${ }^{\mathrm{a}}$ Degrees of freedom.

*Significant at a level of 0.05 . ${ }^{* *}$ Significant at a level of 0.01 .

Multiple regression analysis of the experimental data provided a mathematical model that represented the MK-7 concentration in the experimental region. The relationship that was studied can be expressed by the following secondorder polynomial model equation:

$$
\begin{aligned}
& Y=61.82+2.47^{*} \mathrm{~A}+2.28^{*} \mathrm{~B}+4.57^{*} \mathrm{C}+1.90^{*} \mathrm{~A} * \mathrm{~B}-2.98^{*} \mathrm{~A}^{*} \mathrm{C} \\
& +0.62^{*} \mathrm{~B}^{*} \mathrm{C}-4.29^{*} \mathrm{~A}^{2}-4.34^{*} \mathrm{~B}^{2}-2.43^{*} \mathrm{C}^{2}
\end{aligned}
$$

where $Y$ is the predicted MK-7 concentration $(\mu \mathrm{g} / \mathrm{ml}) ; \mathrm{A}, \mathrm{B}$, and $C$ are the coded values of the test variables, maltose, tryptone, and glycerol concentration, respectively.

The model determination coefficient $\left(R^{2}\right)$ was 0.9419, which indicated that the proposed model could account for $94 \%$ of the variability. The value of the adjusted determination coefficient (Adj $R^{2}=0.8548$ ) was also high enough to advocate for a high significance of the model [23]. The lackof-fit test compared the residual error to the "pure error" from replicated design points. The "lack-of-fit $F$-value" of 19.54 also indicated that lack of fit was not significant $(p=0.17>0.05)$ relative to the pure error. Thus, the estimated models adequately fit the experimental data. At the same time, a relatively lower value of the coefficient of variation $(\mathrm{CV}=5.42 \%)$ indicated improved precision and reliability of the conducted experiments [19]. In addition, the "Adeq. Precision" was used to measure the signal (response)-to- 
A
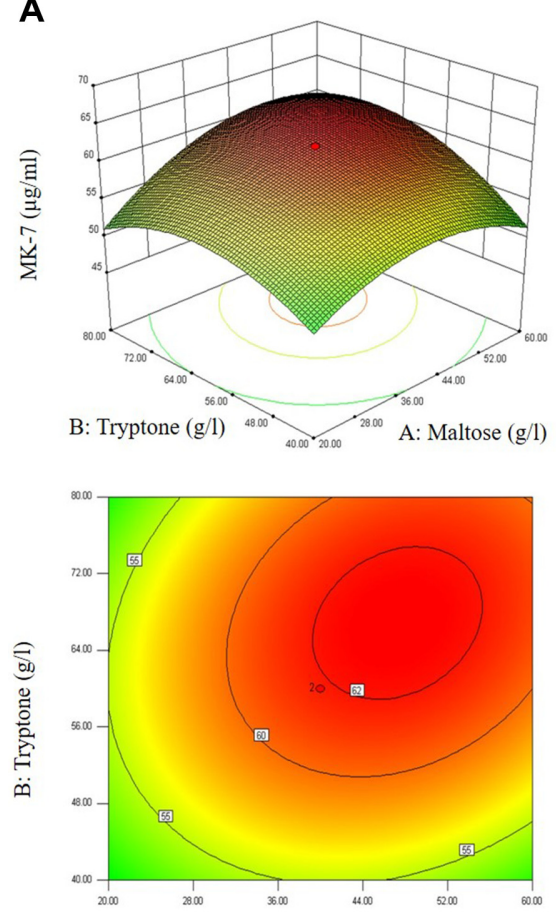

A: Maltose $(g / 1)$
B
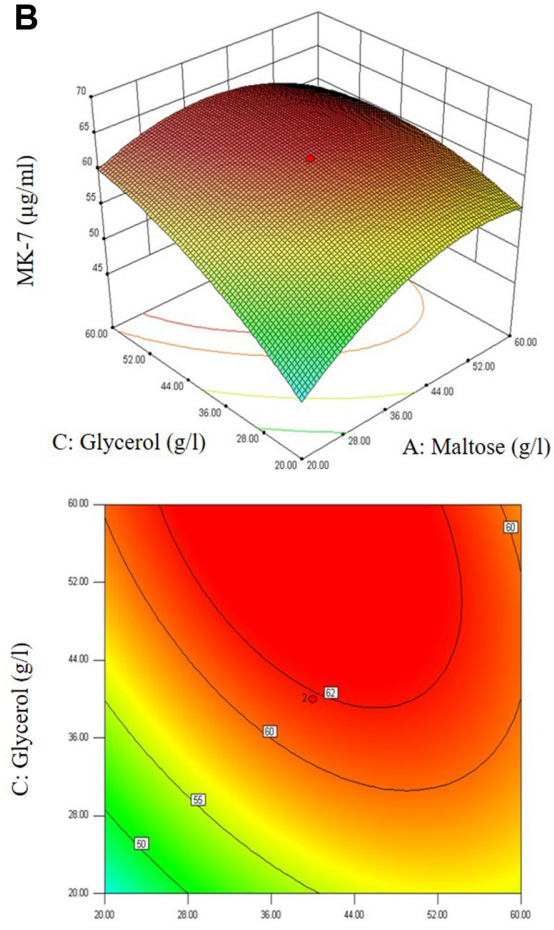

A: Maltose (g/l)
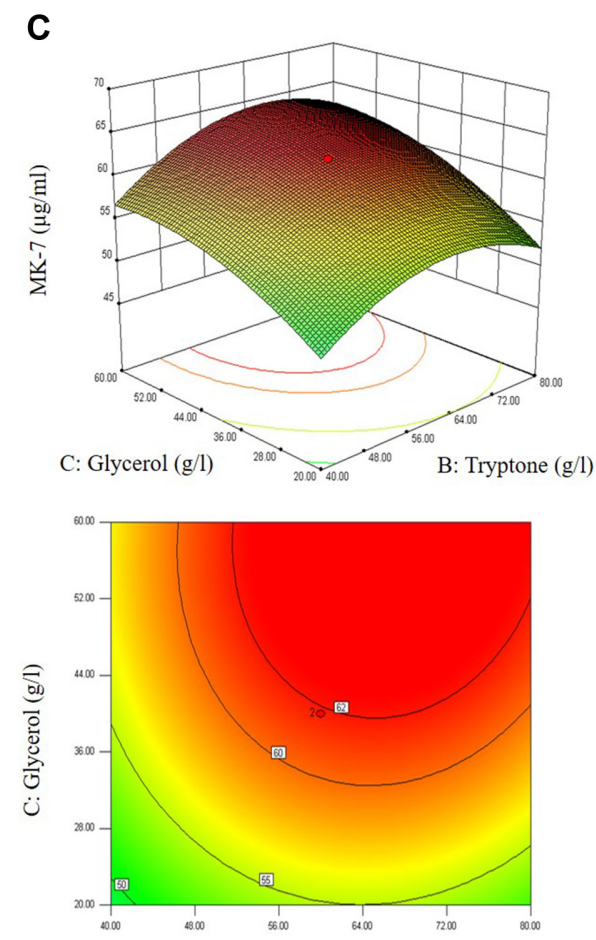

B: Tryptone (g/l)

Fig. 1. Response surface and contour plots for the production of MK-7 by B. subtilis.

(A) Effects of maltose and tryptone concentration. (B) Effects of maltose and glycerol concentration. (C) Effects of tryptone and glycerol concentration.

noise (deviation) ratio, in which a ratio $>4$ was indicative of an adequate signal. In this analysis, the ratio of 9.858 indicated that there was an adequate signal, and that this model can be used to navigate the design space.

To investigate the interactions among the variables and to determine the optimal level of each factor for maximum MK-7 production by B. subtilis, response surface plots and contour plots (Figs. 1A-1C) were obtained based on the model equation. Each plot represents an infinite number of combinations of the two test variables, with the other two maintained at their respective zero level. Fig. 1A depicts the effects of interactions that included ambient maltose $(20-60 \mathrm{~g} / \mathrm{l})$ and tryptone $(40-80 \mathrm{~g} / \mathrm{l})$ with a constant concentration of glycerol at the zero level of $40 \mathrm{~g} / \mathrm{l}$. Both maltose and tryptone demonstrated quadratic effects on the MK-7 yield. Fig. 1B shows that there was a significant mutual interaction between maltose and glycerol, and the optimal maltose concentration was approximately 36$52 \mathrm{~g} / 1$ (Figs. 1A and 1B). A relative comparison between Fig. $1 \mathrm{C}$ and the model equation revealed an insignificant interaction between tryptone and glycerol. These results indicated that MK-7 production was significantly influenced by maltose, tryptone, and glycerol, and that all three factors were key nutrient materials controlling the biosynthesis of MK-7. Higher concentrations of maltose or glycerol could cause a slight inhibition of MK-7 synthesis. This fact was also suggested during other biosynthesis optimization experiments on carbon and nitrogen repression effects [20]. Glycerol displayed a predominant influence on MK-7 production, but its effect was reported not as a carbon source to promote cell growth, but rather as an increased yield of MK-7 on a per-cell basis [12]. Moreover, the effect of glycerol has been speculated to involve decreased viscosity of the medium to provide the optimum balance between water activity and viscosity, stimulating the uptake of extracellular substrates, and enhancing the mass transfer can consequently increase the MK-7 biosynthesis [16]. The optimal levels of the three investigated factors were calculated by solving the regression equation inside the region of the experiments. The highest MK-7 production of $64.18 \mu \mathrm{g} / \mathrm{ml}$, with a $95 \%$ confidence interval between 60.12 and $68.25 \mu \mathrm{g} / \mathrm{ml}$, was predicted by the model for conditions using maltose, tryptone, and glycerol at concentrations of $36.78,62.76$, and $58.90 \mathrm{~g} / \mathrm{l}$, respectively. 


\section{Model Verification}

On the basis of the results of the statistical design, the verification experiments were performed at the predicted medium compositions derived from ridge analysis of RSM. The MK-7 concentration synthesized by B. subtilis was at a remarkably high level of $64.34 \pm 3.43 \mu \mathrm{g} / \mathrm{ml}$ after 5 days of culture, which was within the $95 \%$ confidence interval of the maximum predicted value $(64.18 \mu \mathrm{g} / \mathrm{ml})$. The excellent correlation between the predicted and experimental values verified the validity and adequacy of the predicted model.

In addition, the time course of MK-7 production in the optimized medium $(\mathrm{pH} 7.0$; maltose, tryptone, glycerol, $\mathrm{NaH}_{2} \mathrm{PO}_{4}$, Tween 80, dipicolinic acid, and 1,4-dihydroxy-2naphthoic acid at concentrations of 36.78, 62.76, 58.90, 1.0, $5.0,0.66$, and $0.015 \mathrm{~g} / \mathrm{l}$, respectively) was monitored in this study. The result is shown in Fig. 2. The MK-7 synthesis profile displayed a similar trend to previous studies [12, 13]. Synthesis was dramatically increased between days 2 and 5 of fermentation, and thereafter steadily approached the maximum level of $71.95 \pm 1.00 \mu \mathrm{g} / \mathrm{ml}$ at day 9 during the stationary phase.

This study demonstrated that the use of a factorial CCRD by determining the medium compositions leads to the optimum yield of MK-7 production. Maltose as a carbon source, tryptone as a nitrogen source, and glycerol as an additional activator were the most effective nutrients to enhance MK-7 production by B. subtilis. The maximum MK-7 concentration was achieved in the medium with maltose, tryptone, and glycerol at concentrations of $36.78,62.76$, and $58.90 \mathrm{~g} / \mathrm{l}$, respectively. A second-order polynomial model

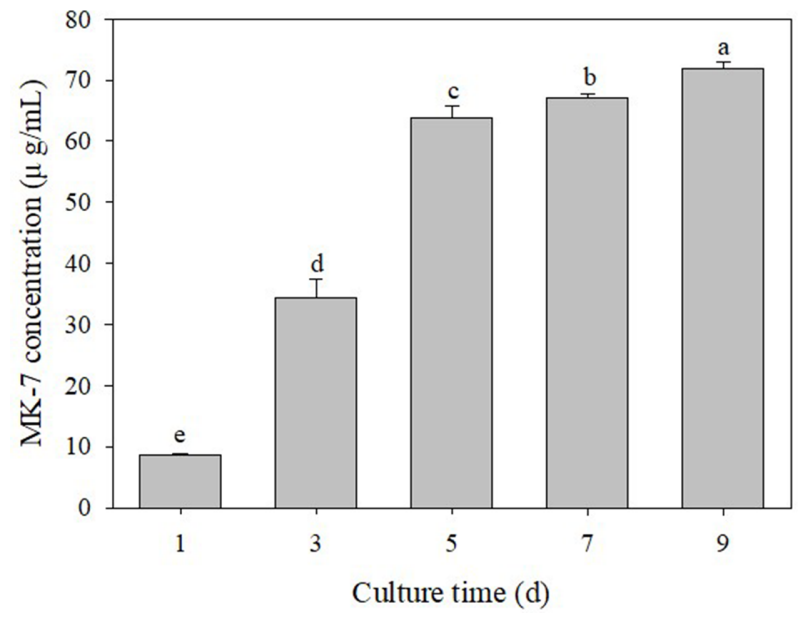

Fig. 2. Time course of MK-7 production by B. subtilis in the optimized medium.

Bars that do not share the same superscript letters are significantly $(p<0.05)$ different from each other. was obtained $\left(R^{2}=0.9419\right)$ indicating that only $5.81 \%$ of the total variations were not explained by the model. The high correlation between the model and the experimental outcomes suggested that RSM offers an efficient and feasible approach to optimize the medium components for maximizing the MK-7 synthesis by B. subtilis. The maximum concentration of MK-7 synthesized by B. subtilis strain KCTC 12392BP reached a remarkably high level of $71.95 \pm 1.00 \mu \mathrm{g} / \mathrm{ml}$ after 9 days of culture with an initial inoculum size of $1 \%(\mathrm{v} / \mathrm{v})$. This value is much higher than that in previous studies $[9,12,13]$.

MK-7 is essential for human health and is highly effective in preventing osteoporosis [4] as well as cardiovascular disease [5]. Therefore, with the increase in yield and productivity, and simultaneous material saving by using RSM, industrial-scale production of MK-7 by B. subtilis in the optimized medium is possible and economically attractive. Further work on optimization of process parameters, such as inoculum size, incubation temperature, initial $\mathrm{pH}$, and dissolving oxygen content, is necessary.

\section{Conflict of Interest}

The authors have no financial conflicts of interest to declare.

\section{References}

1. Stewart JD. 1939. Prothrombin deficiency and the effects of vitamin $\mathrm{K}$ in obstructive jaundice and biliary fistula. Ann. Surg. 109: 588-595.

2. Tsukamoto Y, Kasai M, Kakuda H. 2001. Construction of a Bacillus subtilis (natto) with high productivity of vitamin $\mathrm{K}_{2}$ (menaquinone-7) by analog resistance. Biosci. Biotechnol. Biochem. 65: 2007-2015.

3. Lamson DW, Plaza SM. 2003. The anticancer effects of vitamin K. Altern. Med. Rev. 8: 303-318.

4. Tsukamoto Y. 2004. Studies on action of menaquinone-7 in regulation of bone metabolism and its preventive role of osteoporosis. Biofactors 22: 5-19.

5. Gast GCM, de Roos NM, Sluijs I, Bots ML, Beulens JWJ, Geleijnse JM, et al. 2009. A high menaquinone intake reduces the incidence of coronary heart disease. Nutr. Metab. Cardiovasc. Dis. 19: 504-510.

6. Baldini V, Mastropasqua M, Francucci C, D’Erasmo E. 2005. Cardiovascular disease and osteoporosis. J. Endocrinol. Invest. 28: 69-72.

7. Tsukamoto Y, Ichise H, Kakuda H, Yamaguchi M. 2000. Intake of fermented soybean (natto) increases circulating vitamin $\mathrm{K}_{2}$ (menaquinone-7) and $\gamma$-carboxylated osteocalcin concentration in normal individuals. J. Bone Miner. Metab. 
18: 216-222.

8. Wu WJ, Ahn BY. 2011. Improved menaquinone (vitamin $\mathrm{K}_{2}$ ) production in cheonggukjang by optimization of the fermentation conditions. Food Sci. Biotechnol. 20: 1585-1591.

9. Sato T, Yamada Y, Ohtani Y, Mitsui N, Murasawa H, Araki S. 2001. Production of menaquinone (vitamin $\mathrm{K}_{2}$ )-7 by Bacillus subtilis. J. Biosci. Bioeng. 91: 16-20.

10. Wu WJ, Ahn BY. 2011. Isolation and identification of Bacillus amyloliquefaciens BY01 with high productivity of menaquinone for cheonggukjang production. J. Korean Soc. Appl. Biol. Chem. 54: 783-789.

11. Goodman SR, Marrs BL, Narconis RJ, Olson RE. 1976. Isolation and description of a menaquinone mutant from Bacillus licheniformis. J. Bacteriol. 125: 282-289.

12. Sato T, Yamada $Y$, Ohtani $Y$, Mitsui N, Murasawa H, Araki S. 2001. Efficient production of menaquinone (vitamin $\mathrm{K}_{2}$ ) by a menadione-resistant mutant of Bacillus subtilis. J. Ind. Microbiol. Biotechnol. 26: 115-120.

13. Berenjian A, Mahanama R, Talbot A, Biffin R, Regtop H, Valtchev $P$, et al. 2011. Efficient media for high menaquinone7 production: response surface methodology approach. New Biotechnol. 28: 665-672.

14. Liyana-Pathirana C, Shahidi F. 2005. Optimization of extraction of phenolic compounds from wheat using response surface methodology. Food Chem. 93: 47-56.

15. Sin HN, Yusof S, Sheikh Abdul Hamid N, Rahman RA. 2006. Optimization of enzymatic clarification of sapodilla juice using response surface methodology. J. Food Eng. 73: 313-319.

16. Berenjian A, Mahanama R, Talbot A, Regtop H, Kavanagh J,
Dehghani F. 2012. Advances in menaquinone-7 production by Bacillus subtilis natto: fed-batch glycerol addition. Am. J. Biochem. Biotechnol. 8: 105-110.

17. Sumi H, Ikeda S, Ohsugi T. 2009. Increasing the production of nattokinase and vitamin $\mathrm{K} 2$ in natto with dipicolinic acid. Open Food Sci. J. 2: 10-14.

18. Berenjian A, Chan NC, Mahanama R, Talbot A, Regtop H, Kavanagh J, et al. 2013. Effect of biofilm formation by Bacillus subtilis natto on menaquinone-7 biosynthesis. Mol. Biotechnol. 54: 371-378.

19. Frey DD, Engelhardt F, Greitzer EM. 2003. A role for 'onefactor-at-a-time' experimentation in parameter design. Res. Eng. Des. 14: 65-74.

20. Adinarayana K, Ellaiah P. 2002. Response surface optimization of the critical medium components for the production of alkaline protease by a newly isolated Bacillus sp. J. Pharm. Pharm. Sci. 5: 272-278.

21. Jafari Nejad S, Abolghasemi H, Moosavian MA, Golzary A, Maragheh MG. 2010. Fractional factorial design for the optimization of hydrothermal synthesis of lanthanum oxide nanoparticles under supercritical water condition. J. Supercrit. Fluids 52: 292-297.

22. Guo WQ, Ren NQ, Wang XJ, Xiang WS, Ding J, You Y, et al. 2009. Optimization of culture conditions for hydrogen production by Ethanoligenens harbinense B49 using response surface methodology. Bioresour. Technol. 100: 1192-1196.

23. Elibol M. 2004. Optimization of medium composition for actinorhodin production by Streptomyces coelicolor A3(2) with response surface methodology. Process Biochem. 39: 1057-1062. 